\title{
Effect of tool pin geometry and weld pass number on microstructural, natural aging and mechanical behaviour of $\mathrm{SiC}$-incorporated dissimilar friction-stir-welded aluminium alloys
}

\author{
MOHAMMAD MAHDI MORADI, HAMED JAMSHIDI AVAL* \\ and ROOHOLLAH JAMAATI $\mathbb{D}$ \\ Department of Materials Engineering, Babol Noshirvani University of Technology, Shariati Avenue, \\ Babol 47148-71167, Iran \\ e-mail: h.jamshidi@nit.ac.ir
}

MS received 3 May 2018; revised 9 August 2018; accepted 14 August 2018; published online 18 December 2018

\begin{abstract}
The aim of this investigation was to study the effect of tool pin geometry and pass number on mechanical and microstructural behaviour of SiC-incorporated dissimilar friction stir welding of 6-mm-thick plates of AA6061-T6 and AA2024-T351. Two tool pin geometries, square and triangle frustum, were used. It was found that the weld made by square frustum pin and two passes with rotation in the same direction produces more homogenized and finer distribution of $\mathrm{SiC}$ particles. Also, the grain size of stir zone in the weld made by two passes is finer than that made by one pass. The weld made by triangle frustum pin shows higher thermomechanically affected zone hardness, natural aging kinetics and tensile strength than the others.
\end{abstract}

Keywords. Dissimilar friction stir welding; aluminium alloys; SiC particles; tool geometrical parameters.

\section{Introduction}

Friction stir welding (FSW) as a solid-state sever plastic deformation joining process is one of the simplest and welldeveloped techniques for welding aluminium alloys. A rotating non-consumable tool is inserted in the workpiece interface and the heat generated by the tool softens the material in the joint line. The softened material stirs around the tool and gets extruded from leading side of the tool to the trailing side. Besides, as a novel approach in the FSW of materials firstly proposed by Sun and Fujii [1], addition of ceramic reinforcement particles in the joint line by making metal matrix composite (MMC) in the stir zone (SZ) improved the joint properties. Accordingly, successful works have been performed to investigate various aspects of FSW process on dissimilar joining of aluminium alloys [2-9]. However, according to the literature, there are limited works on the effect of geometric tool parameters on FSW of AA6xxx and AA2xxx series.

Li et al [10] studied the complex flow patterns developed in the dissimilar FSW of 6.5-mm-thick AA2024 and AA6061 alloys using differential etching behaviour of alloys. They used a cylindrical pin; rotation speeds were varied between 400 and $1200 \mathrm{rpm}$, and the travel speed was constant at $1 \mathrm{~mm} / \mathrm{s}$. They reported complex vortex, whorl and swirl features in the SZ that are characteristic of

*For correspondence anarchic mixing produced by accommodating alloys lamellae. Ouyang and Kovacevic [11] investigated the effect of welding rotational and transverse speeds on microand macrostructural aspects of dissimilar friction-stir-welded 12.7-mm-thick AA2024-T3 and AA6061-T6 alloys. They found that mechanical mixing of material and material flow patterns changed with welding speed. With increasing rotational/traverse speed ratio, more uniform and rounder lamellae of different alloys are produced in the weld nugget. Also, the microstructural changes in the nugget zone result in hardness fluctuations in cross sections of joints. Amancio et al [12] studied dissimilar FSW of 4-mm-thick AA2024-T351 and AA6056-T4 alloys by varying rotational speed (500-1200 rpm) and the welding speed (150-400 $\mathrm{mm} / \mathrm{min}$ ) and using a threaded cylindrical pin. They reported that defect-free and the strongest joints (90\% of AA6065-T4 strength) can be achieved at $800 \mathrm{rpm}$ and welding speed of $150 \mathrm{~mm} / \mathrm{min}$. Also, they show that the joint component with the greatest strength reduction controls the performance of the joint. Cavaliere et al [13] studied the mechanical and microstructural properties of dissimilar 4-mm-thick AA6082-T6 and AA2024-T3 friction-stir-welded joints using two traverse speeds of 80 and $115 \mathrm{~mm} / \mathrm{min}$ and the constant rotational speed $1600 \mathrm{rpm}$ with a conical pin tool. They reported that the vertical force increases on positioning AA2024 in the advancing side and increasing traverse speed. Also, the joint made using traverse speed of $115 \mathrm{~mm} / \mathrm{min}$ and AA6082 on the advancing 
Table 1. Chemical composition of alloys (wt \%).

\begin{tabular}{lccccccc}
\hline Alloy & $\mathrm{Al}$ & $\mathrm{Mg}$ & $\mathrm{Si}$ & $\mathrm{Fe}$ & $\mathrm{Cu}$ & $\mathrm{Cr}$ & $\mathrm{Mn}$ \\
\hline AA2024-T351 & Base & 0.68 & 0.47 & 0.40 & 0.19 & 0.19 & 0.06 \\
AA6061-T6 & Base & 1.2 & 0.50 & 0.50 & 3.80 & 0.10 & 0.30 \\
\hline
\end{tabular}

Table 2. Mechanical properties of alloys.

\begin{tabular}{lcccc}
\hline Alloy & $\begin{array}{c}\text { Tensile } \\
\text { strength } \\
(\mathrm{MPa})\end{array}$ & $\begin{array}{c}\text { Yield } \\
\text { strength } \\
(\mathrm{MPa})\end{array}$ & $\begin{array}{c}\text { Elongation } \\
(\%)\end{array}$ & $\begin{array}{c}\text { Hardness } \\
(\mathrm{VHN})\end{array}$ \\
\hline $\begin{array}{c}\text { AA2024- } \\
\text { T351 }\end{array}$ & 469 & 324 & 19 & 137 \\
$\begin{array}{c}\text { AA6061- } \\
\text { T6 }\end{array}$ & 310 & 278 & 12 & 107 \\
\hline
\end{tabular}

side shows the best tensile and fatigue properties. Izadi et al [14] studied the material flow in the weld nugget of a dissimilar joint of 6.35-mm-thick AA2024-T351 and AA6061T6 made by three FSW tool pin profiles (grooved pin, three-flat pin and threaded pin). They show that a three-flat pin imposes vertical material flow, which results in better material mixing in the SZ. Also, on using a grooved pin and AA2024 positioned in the advancing side, the intermixed lamella of material in the weld nugget cannot be seen.

Although a few works have been conducted to investigate the effects of tool pin geometry in dissimilar FSW of aluminium alloys, the effect of tool pin geometry and FSW pass number in dissimilar FSW of two age-hardenable aluminium alloys AA6061 and AA2024 with incorporated ceramic reinforcement particles has never been investigated. In this work, dissimilar FSW of AA6061-T6 and AA2024-T351 was carried out using $\mathrm{SiC}$ particles in the joint line, and the effects of tool pin geometry, number and direction of FSW passes and natural aging behaviour of joints have been investigated.

\section{Experimental}

The AA2024-T351 and AA6061-T6 aluminium plates used for the butt FSW had dimensions of $100 \mathrm{~mm} \times 50 \mathrm{~mm} \times$ $6 \mathrm{~mm}$. The chemical composition and mechanical properties of aluminium plates are presented in tables 1 and 2. A groove with dimensions of $90 \mathrm{~mm}$ length, $0.15 \mathrm{~mm}$ width and $5.8 \mathrm{~mm}$ depth was created on the side of plates that were welded together. After the plates were clamped on the back plate, $\mathrm{SiC}$ microparticles ranging $11-18 \mu \mathrm{m}$ in size were applied into the groove and pressed tightly. Figure 1 displays the square and triangle frustum tools used in this
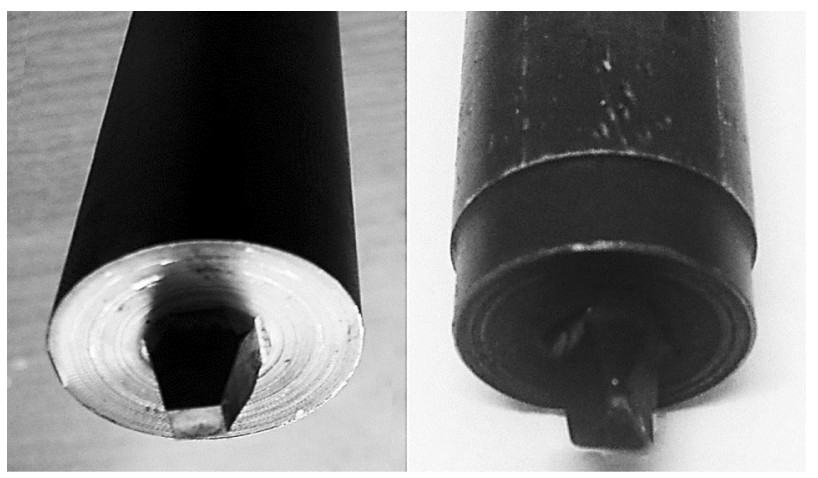

Figure 1. The tools geometry used in this study.

Table 3. Welding parameters used in the experiments.

\begin{tabular}{lccc}
\hline Sample & Pin geometry & $\begin{array}{c}\text { Pass } \\
\text { number }\end{array}$ & $\begin{array}{c}\text { Second rotational } \\
\text { direction }\end{array}$ \\
\hline A & Square frustum & 1 & - \\
B & $\begin{array}{c}\text { Triangle } \\
\text { frustum }\end{array}$ & 1 & - \\
C & Square frustum & 2 & Same direction \\
D & Square frustum & 2 & Inverse direction \\
\hline
\end{tabular}

study. Both of them have an 18-mm diameter shoulder with a $2^{\circ}$ conical cavity and a frustum pin $5.8 \mathrm{~mm}$ in length. The inscribed circle diameter up and down of the pin is 7 and $3.5 \mathrm{~mm}$, respectively. The AA6061 aluminium alloy was located in the retreating side. To study the effect of number of FSW passes on the joint, welding was done in one pass and two passes. Besides, the second pass was performed in two rotational directions, same and inverse directions, in comparison with the first pass. The welding conditions investigated in this study are listed in table 3 . The constant welding speeds and groove dimensions used in this investigation are selected by several tests to determine the set of welding parameters that give sound welds.

The microstructural issues of joints are investigated using a Dewinter optical microscope and a VEGA3 TESCAN electron microscope on a cross section of the welds perpendicular to the welding direction. Keller's reagent and modified Polton solution were employed to etch the AA2024 and AA6061 alloys, respectively. EDS analyses were performed to determine element distribution in the weld nugget. The Vickers micro-hardness was also measured using a Koopa-MH3 Vickers indenter on cross sections of welded samples with a test load of $100 \mathrm{gf}$ for $15 \mathrm{~s}$ according to ASTM E92 [15]. To evaluate tensile strengths of the welded samples, the tensile test sub-size specimens were prepared according to ASTM E8M [16]. By flat surface finishing of tensile test specimens, the effect of shoulder irregularities on the joint strength was removed. 


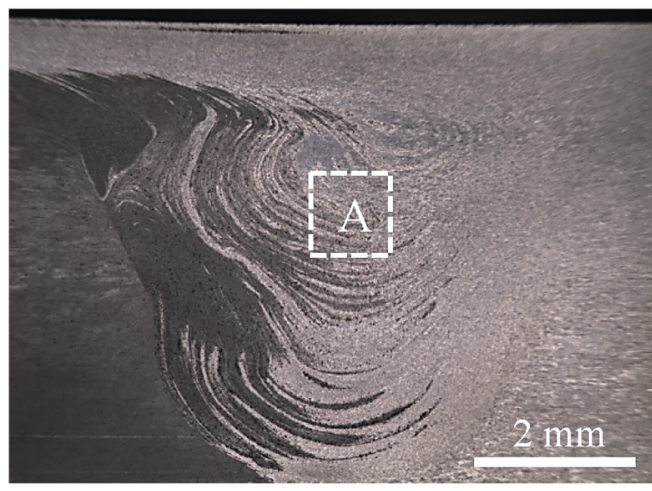

(a)

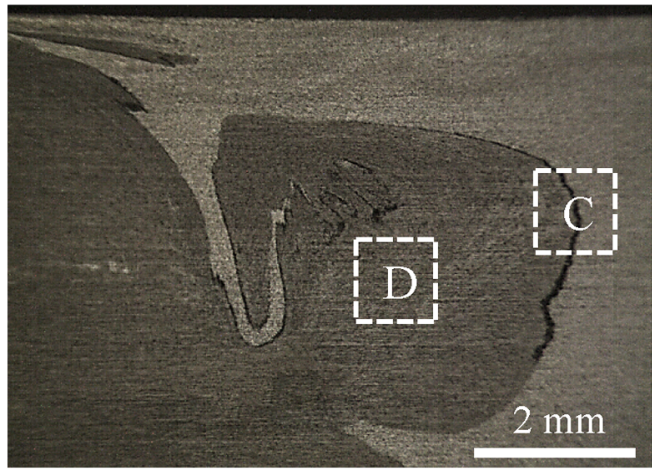

(c)

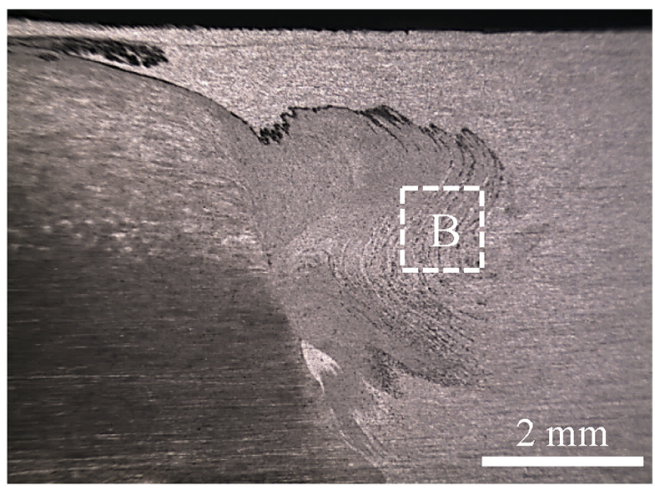

(b)

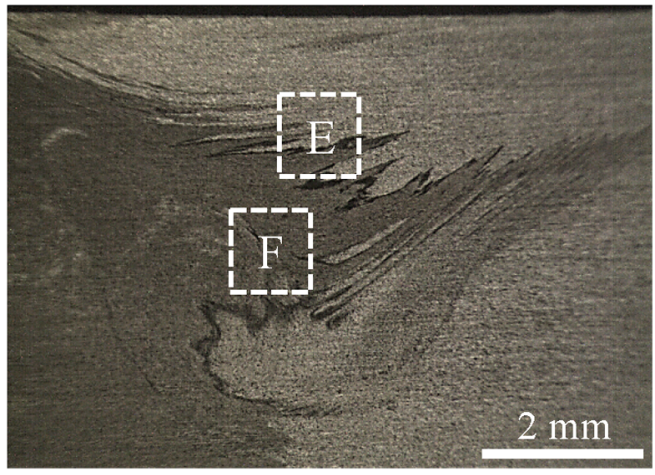

(d)

Figure 2. Optical micrograph of friction-stir-welded samples: (a) sample A, (b) sample B, (c) sample C and (d) sample D.

\section{Results and discussion}

Optical micrographs of friction-stir-welded samples are shown in figure 2. AA2024 is located in the left hand side of figures and etched darker than AA6061 alloy. It can be seen that sample A welded by a square pin, compared with sample B, welded by a triangle pin, has a more interleaved layer of materials in the weld nugget. Besides, the $\mathrm{SiC}$ particles agglomeration near tool shoulder of sample B is more visible than in sample A. The tool pin geometry and welding speed (rotational and traverse speeds) have a strong effect on material flow in the weld nugget $[17,18]$. According to past research [19] on the effect of number of flat surfaces of pin on material flow in the weld nugget, the pulsating stirring action and eccentricity of tool due to flat faces of pin control flow of plasticized material in the weld nugget. As reported in [20], a triangular pin can stir a greater material volume compared with a circular pin as well as polygonal pins with higher number of sides. One of the objectives of our research was increasing weld nugget homogeneity. Since the triangular and square-shaped tool probes can stir a greater material volume, we choose these types of pin in our study. The higher eccentricity, i.e., the higher ratio of the dynamic volume swept by the tool to the static volume of the tool, results in easier flow of material around the pin. The square and triangle frustum pin has eccentricity of 3.14 and 1.22 , respectively. The higher pulsation per second, i.e., rotational speed in seconds $\times$ number of flat faces, led to more effective stirring. The square and triangle frustum pin at rotational speed of $800 \mathrm{rpm}$ has pulsation of 53 and 40 pulse per second, respectively. Therefore, the higher eccentricity and pulsating action of square frustum pin produce more homogenized weld nuggets (figures $3 a$ and $b$ ).

With increasing weld pass number the interleaved layer structure disappeared and in sample $\mathrm{C}$, an agglomeration band of particles appeared (figure $3 \mathrm{c}$ ). This agglomeration band becomes wavy in sample $\mathrm{D}$ with changing direction of tool rotation in the second pass (figures $2 d$ and $3 e$ ). SEM investigation at the centre of weld nugget (figures $3 \mathrm{~d}$ and $\mathrm{f}$ ) shows that the $\mathrm{SiC}$ particles are uniformly distributed. In sample D, inversing tool rotation results in a thicker agglomerated band and smaller area with uniform distribution of $\mathrm{SiC}$ particles in the weld nugget. Also, comparing weld cross sections of samples A, C and D shows that the volume of AA6061 alloy (light colour part near the top of weld nugget) extruded to the AA2024 side in sample D is higher than that in the others. Although the $\mathrm{SiC}$ particles homogeneity increases at the weld centre on increasing weld pass number, the agglomerated band formed in these 


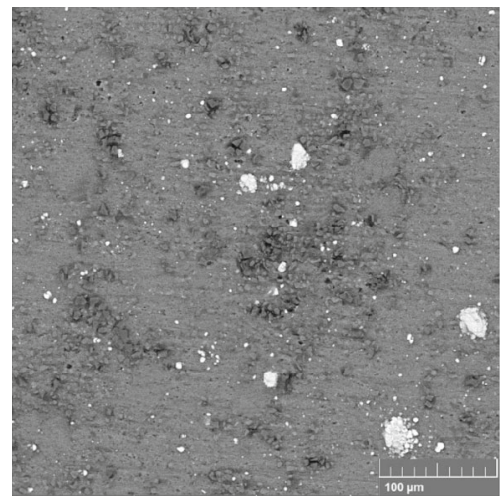

(a)

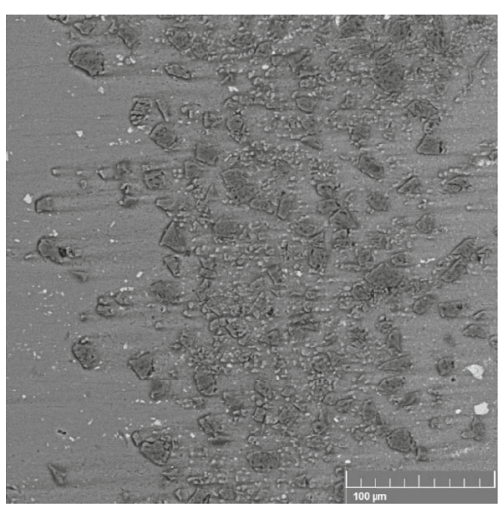

(c)

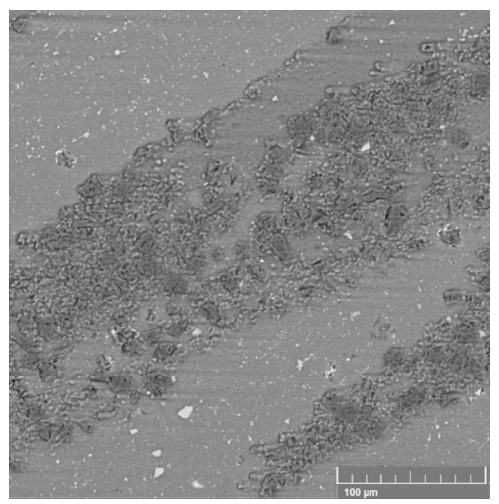

(e)

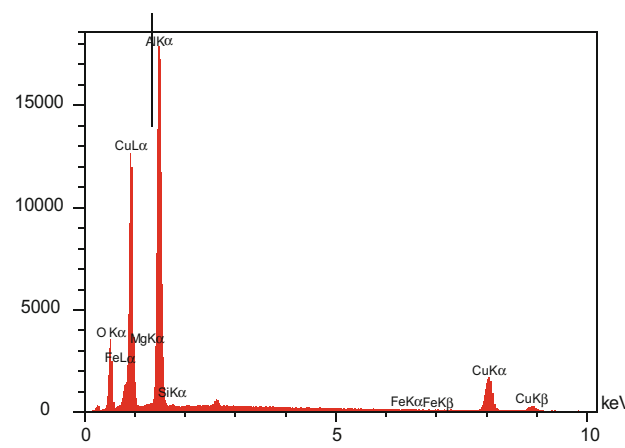

(g)

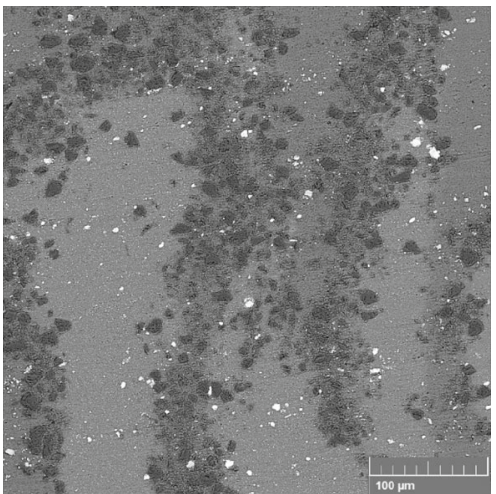

(b)

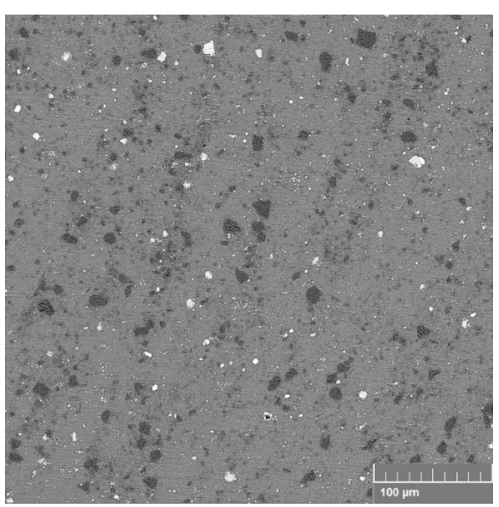

(d)

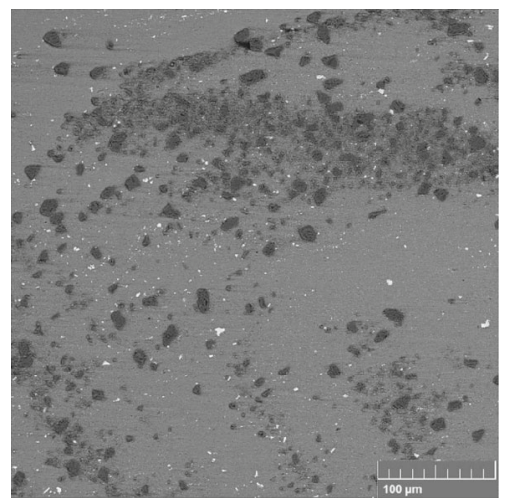

(f)

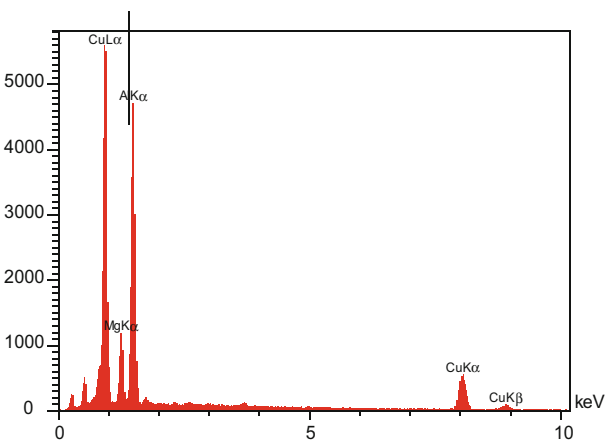

(h)

Figure 3. SEM image of various zones of weld nugget marked in figure 2: (a) zone A, (b) zone B, (c) zone C, (d) zone D, (e) zone E, (f) zone F and EDS analysis of white particles in the SEM micrograph rich in (g) iron and (h) copper. 


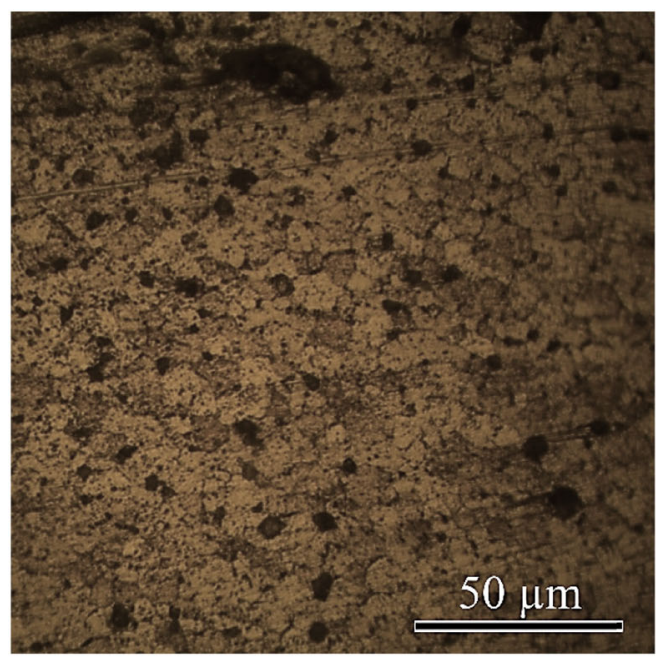

(a)

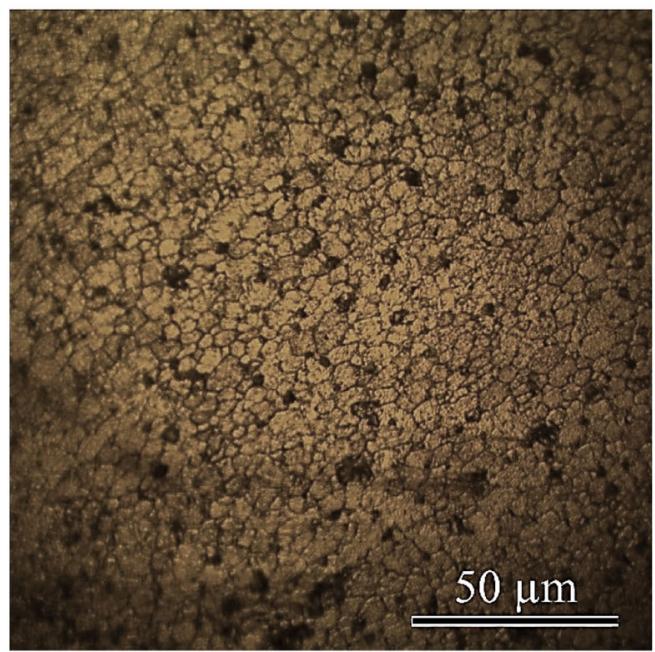

(c)

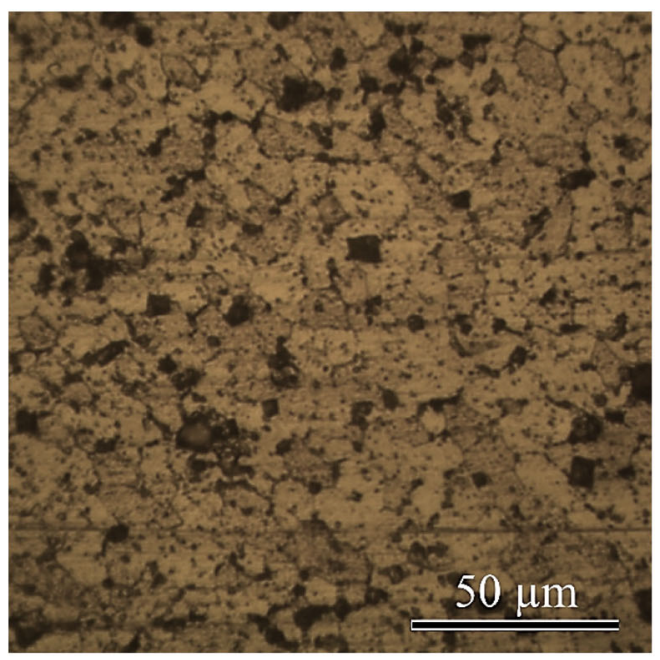

(b)

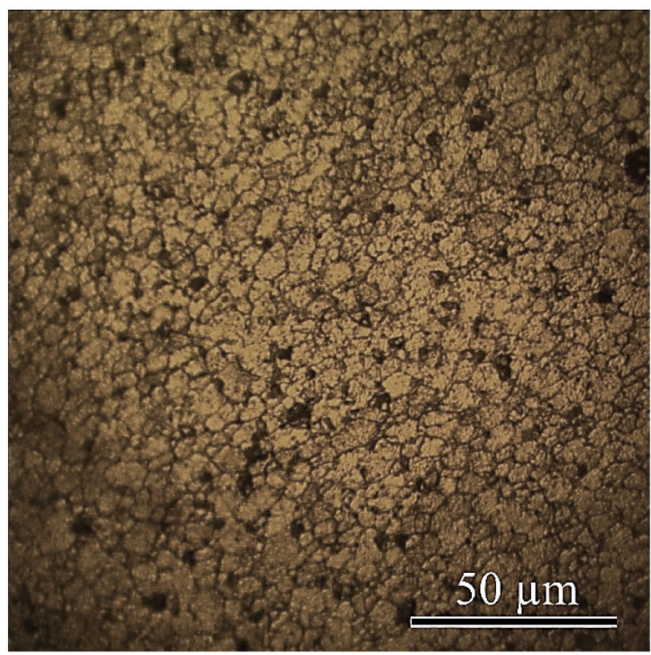

(d)

Figure 4. Microstructure of weld nugget of (a) sample A, (b) sample B, (c) sample C and (d) sample D.

joints can show adverse effect on weld strength. According to figure $3 \mathrm{~g}$ and $\mathrm{h}$ the white particles in the SEM micrograph of AA6061 and AA2024 side are rich in iron and copper particles as verified in EDS analysis, respectively.

The effect of tool pin profile, weld pass number and rotational direction on the microstructure of the welds nugget centre is shown in figure 4 . The microstructure of the weld nugget consists of fine equi-axed grains. The formation of the equi-axed grain structure in FSWed welds is commonly referred to as dynamic recrystallization and is a prominent effect of grain refinement in weld nugget [21]. Addition of second-phase particles influences the grain growth by increasing the number of recrystallized grains nuclei sites and Zener pining effect. In the MMCs, the second-phase particles, by applying pinning pressure, counteract pushing driving force of moving boundary during grain growth. This pinning pressure increases with decreasing particle size and/ or increasing particles volume fraction. It can be seen that in the weld made with square frustum pin, the SZ grain size is smaller than that with triangle frustum pin. The SZ grain size of sample A and B is $8.1 \pm 1.2$ and $10.2 \pm 1.3 \mu \mathrm{m}$, respectively. It may be due to the effect of higher number of flat surfaces of square frustum pin that produce higher plastic deformation and more homogenized distribution of $\mathrm{SiC}$ particles that control recrystallization and grain growth in the weld nugget. Increasing weld pass number in both rotational same and inverse directions leads to smaller SZ grain size. The smaller initial grain size in the weld nugget zone and more homogenized and finer distribution of $\mathrm{SiC}$ particles result in smaller SZ grain size in the welds made by two passes. Considering figure $4 \mathrm{c}$ and $\mathrm{d}$ it appears that the weld made with two passes of rotation in the same direction, due to the production of more homogenized distribution of $\mathrm{SiC}$ particles in the weld nugget than the weld made in inverse 


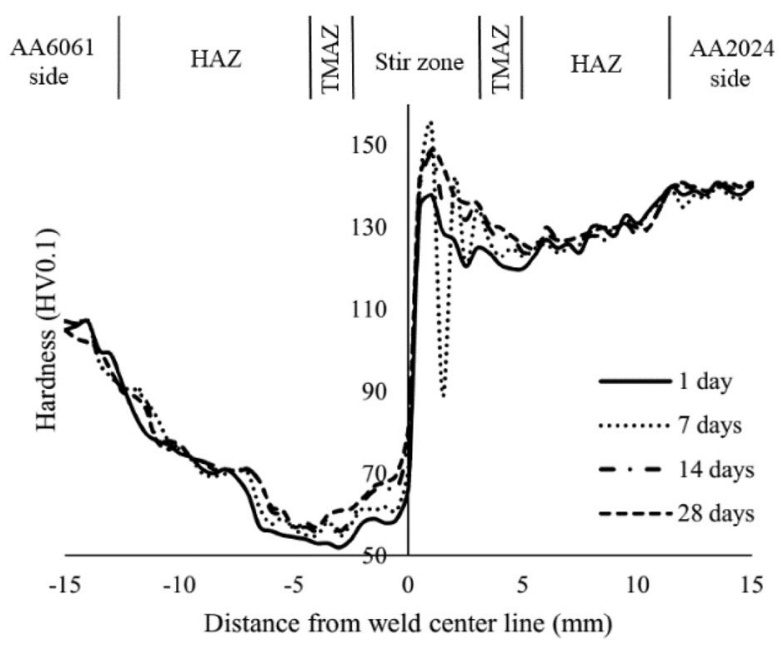

(a)

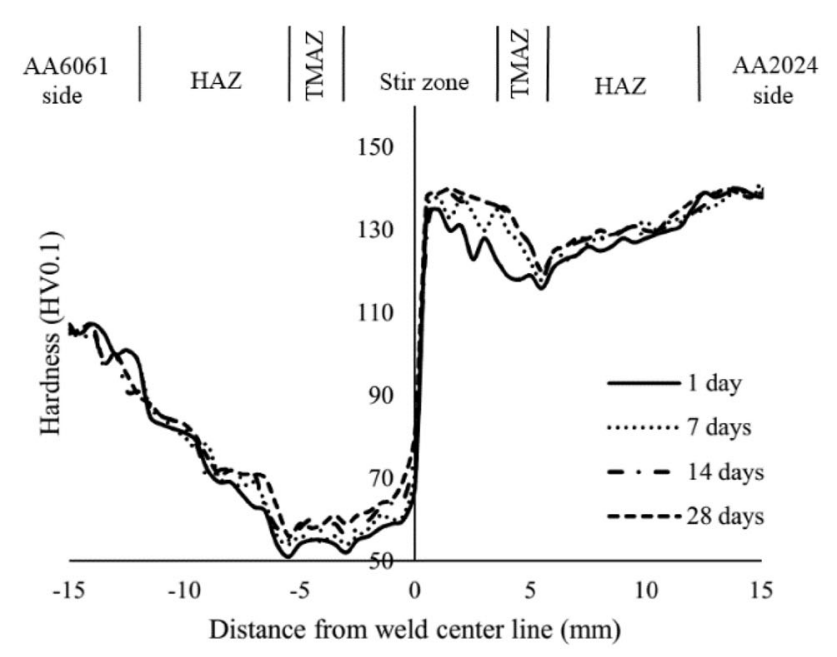

(c)

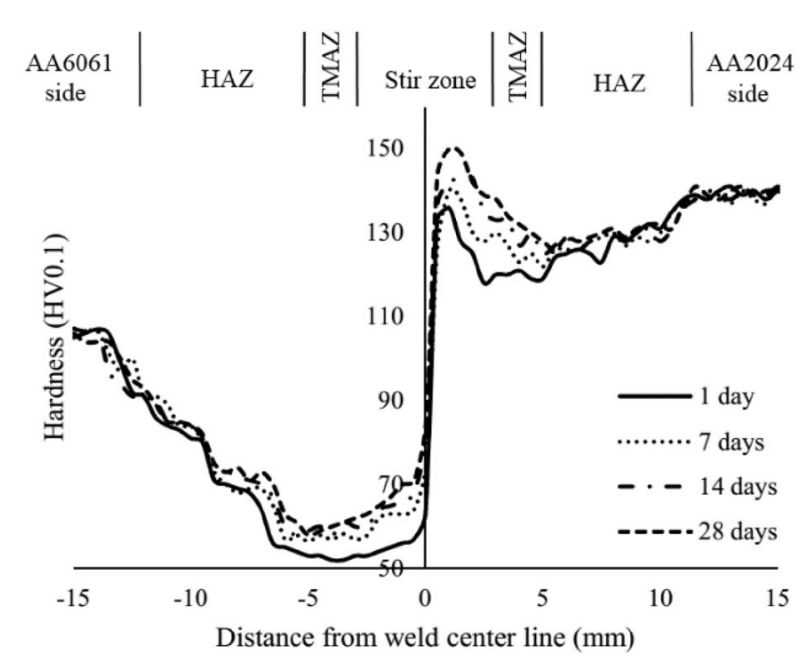

(b)

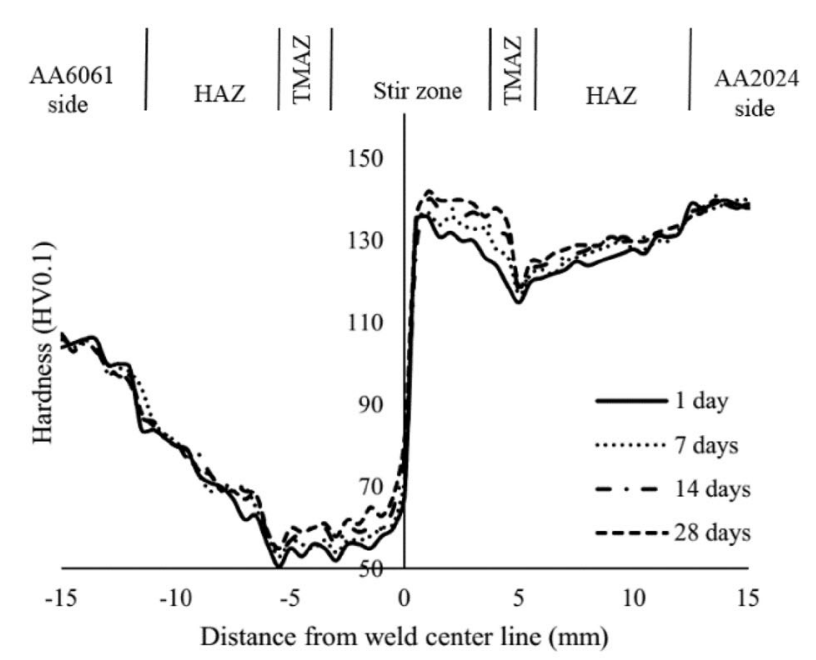

(d)

Figure 5. Microhardness profile for different aging periods after FSW of weld cross section of (a) sample A, (b) sample B, (c) sample C and (d) sample D.

direction, yields finer grain in the nugget. The $\mathrm{SZ}$ grain size of sample $C$ and $D$ is $5.8 \pm 0.9$ and $6.5 \pm 0.7 \mu \mathrm{m}$, respectively.

Figure 5 shows the horizontal hardness profiles across the joints measured at mid-thickness of weld cross section for different aging periods after FSW, where AA6061-T6 and AA2024-T351 base metals show average Vickers hardness of about 107HV0.1 and 137HV0.1, respectively. In the precipitate-hardened 6061 and 2024 aluminium alloys, the imposed weld thermal cycles as well as severe hot deformation lead to elimination of the precipitation hardening effect and finally an abrupt decrease in hardness profile can be observed, as mentioned previously in other publications [22, 23]. The minimum hardness of all samples is in the thermo-mechanically affected zone (TMAZ) of AA6061 side. It can be seen that sample B exhibits higher nugget hardness and TMAZ minimum hardness than those in the others. It is worth noting that samples $\mathrm{C}$ and $\mathrm{D}$, because of more heat applied during two passes, show lower hardness in the weld nugget and TMAZ of AA6061 side. Considering that welding rotational and travel speeds are the same in both samples A and B, the only difference that can control heat input in samples A and B is tool pin profile. The lower contact surface due to three flat surfaces of triangle frustum pin compared with four flat surfaces in square frustum pin results in lower heat production by friction and plastic deformation heat generation. Therefore, lower heat input in sample B results in higher cooling rate; thus, one expects that the amount of precipitates just after welding is lower in the weld zones of this sample than in sample A. However, as shown in figure 6, due to re- 


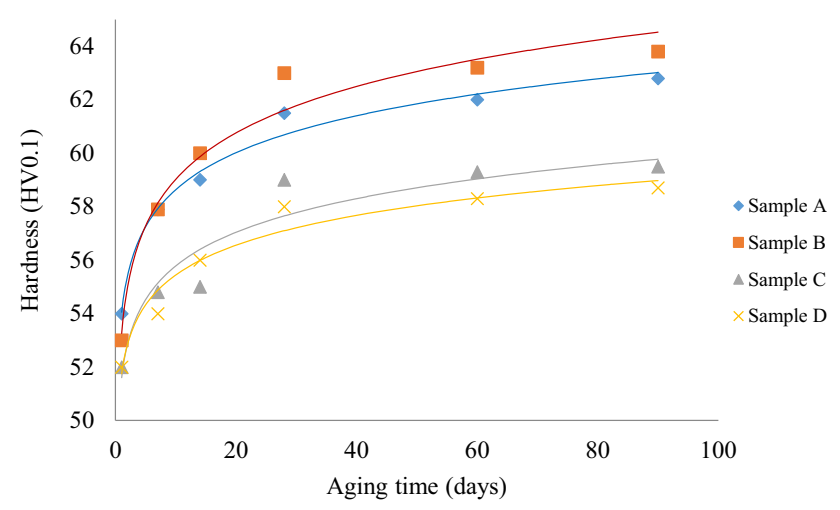

(a)

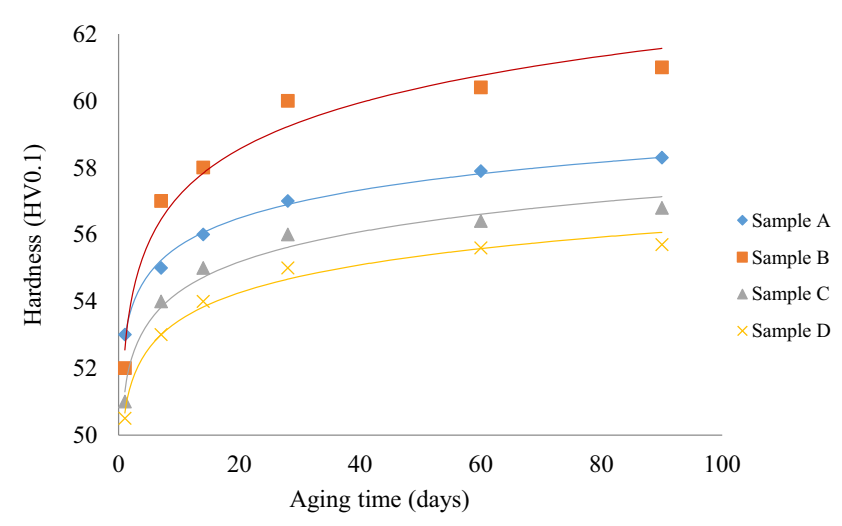

(b)

Figure 6. Hardness versus aging time of welded samples: (a) stir zone and (b) TMAZ.

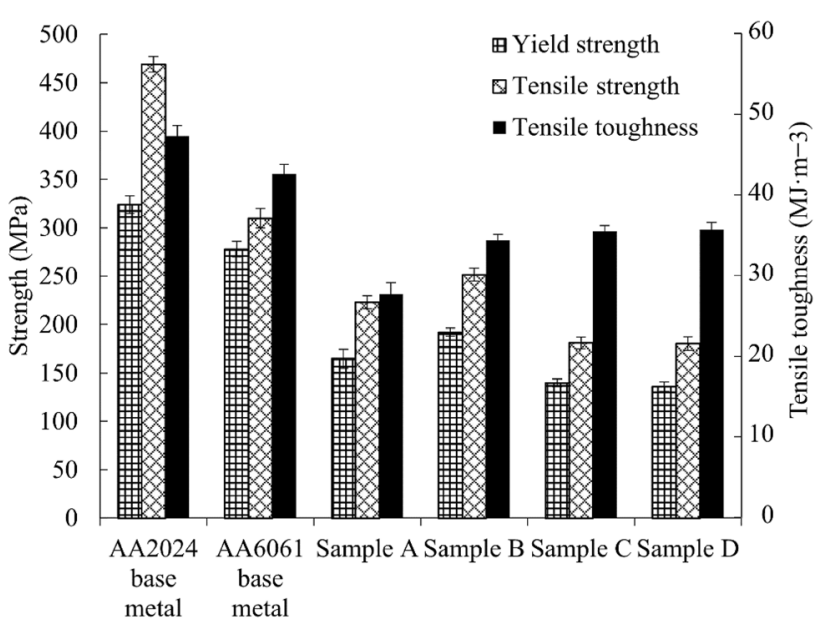

Figure 7. Tensile strength and toughness of welded joints.

precipitation after natural aging, hardness in the weld nugget and TMAZ of samples increases. It can be seen in the image that the aging effect is more pronounced in the first few days. As shown in sample B, increasing of hardness after natural aging is more than those in the others. This may be because of higher cooling rate due to lower heat input in sample B.

The results of the tensile strength and toughness of welded joints after 70 days natural aging are shown in figure 7. It is worth noting that fracture in tensile samples occurs in TMAZ of AA6061 side where a minimum of hardness is observed; see figure 5. It can be seen that sample B shows higher yield strength (YS) and tensile strength (UTS) than those of the others. As shown in figure 5, higher hardness in TMAZ of sample B may be the agent of higher strength in this sample. Besides, lower strength in samples $\mathrm{C}$ and $\mathrm{D}$ can be related to lower hardness in the TMAZ of AA6061 side and SiC agglomerated band formed in the SZ, which results in inhomogeneous mechanical properties across the weld joint. Considering the hardness profile and minimum hardness of samples C and $\mathrm{D}$, the lower tensile strength of sample D may be due to thicker SiC agglomerated band and smaller area with uniform distribution of $\mathrm{SiC}$ particles. As seen, the welds made by two passes show higher tensile toughness than those of the others. The higher elongation and not too low tensile strength result in higher amount of tensile toughness in the welds made by two passes. The SEM image of fracture surfaces of welded samples is shown in figure 8. Both dimples and tear ridges are evident in the fracture surface of samples A and B. This fracture feature represents quasicleavage fracture mode. The fracture surface of samples $\mathrm{C}$ and $\mathrm{D}$ is covered by only large and deep dimples, which indicates ductile fracture. Considering the agglomerated $\mathrm{SiC}$ particles band in the weld nugget of samples $\mathrm{C}$ and $\mathrm{D}$, it is expected that tear ridges exist in the fracture surface of these joints but the lower hardness in the TMAZ of AA6061 side and more homogenous distribution of SiC particles in the SZ can overcome the effect of agglomerated $\mathrm{SiC}$ particles band in the weld nugget. Therefore, dimple fracture surface appears in samples C and D.

\section{Conclusions}

The effect of tool pin geometry and pass number on microstructure and mechanical behaviour of dissimilar friction stir welds of AA6061-T6 and AA2024-T351 reinforced with $\mathrm{SiC}$ microparticles was studied in this research. The results can be summarized as follows:

1. The higher eccentricity and pulsating action of square frustum pin produce more homogenized and effective distribution of $\mathrm{SiC}$ particles in the weld nugget.

2. With increasing weld pass number the interleaved layer structure disappeared and the $\mathrm{SiC}$ particles homogeneity increased at the weld centre. Besides, an agglomeration 


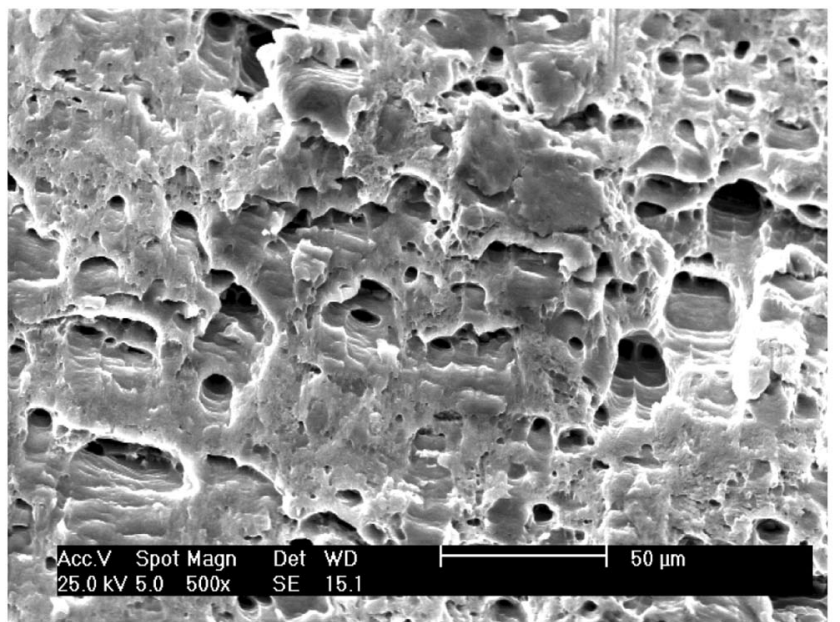

(a)

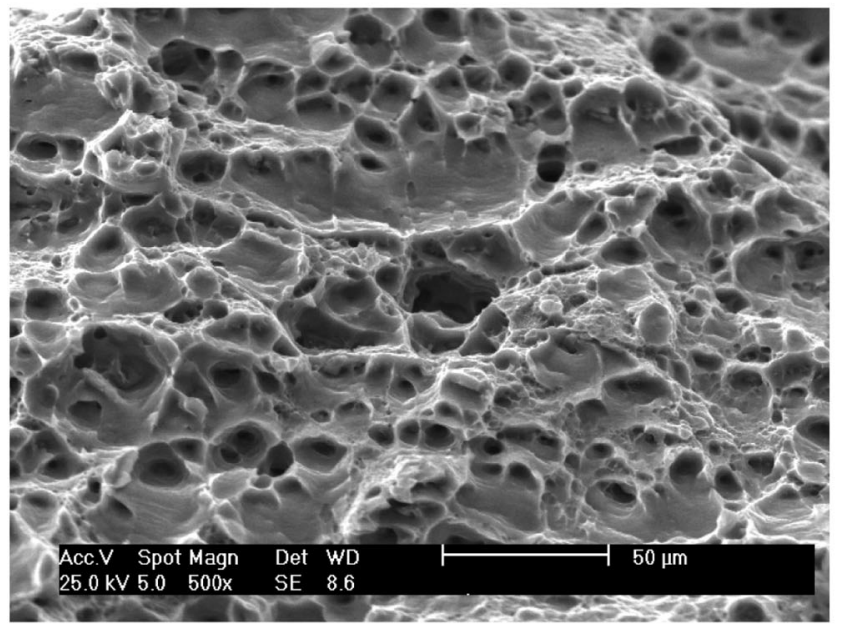

(c)

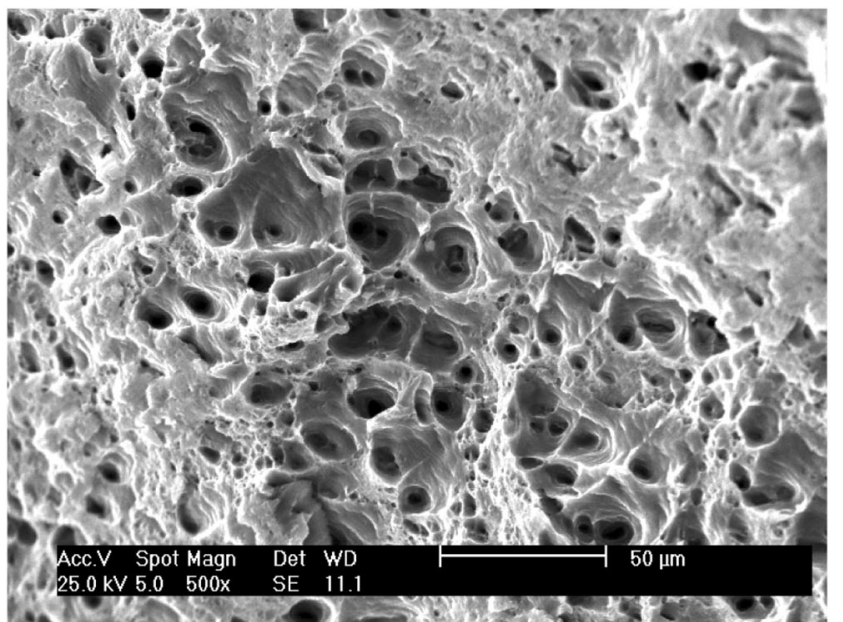

(b)

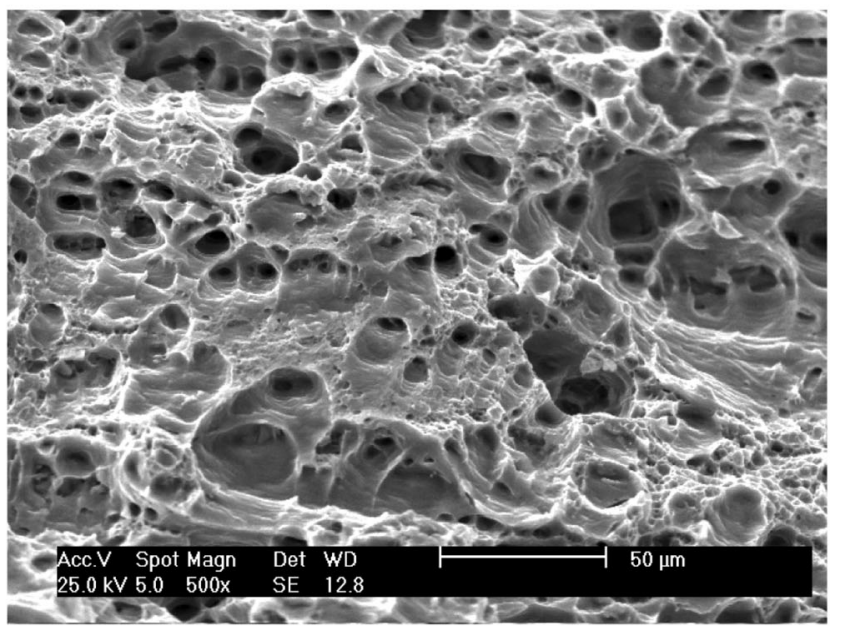

(d)

Figure 8. SEM image of fracture surface of (a) sample A, (b) sample B, (c) sample C and (d) sample D.

band of particles appeared in the weld nugget; this agglomeration band became wavy and thicker with changing direction of tool rotation in the second pass.

3. The plastic deformation and homogenized distribution of $\mathrm{SiC}$ particles control recrystallization and grain growth in the weld nugget. Thus, the weld made by square frustum pin and two passes with rotation in the same direction, due to more homogenized and finer distribution of SiC particles, results in smaller SZ grain size.

4. Increasing weld pass number, due to more heat applied during welding, results in lower hardness in the weld nugget and TMAZ of AA6061 side. Also, the driving force for natural aging after welding in the weld by two passes decreased. The weld made by triangle frustum pin shows higher TMAZ hardness, YS and tensile strength (UTS) than those of the others.

\section{References}

[1] Sun Y and Fujii H 2011 The effect of SiC particles on the microstructure and mechanical properties of friction stir welded pure copper joints. Mater. Sci. Eng. A 528: 5470-5475

[2] Khan N, Siddiquee A, Khan Z and Mukhopadhyay A 2017 Mechanical and microstructural behavior of friction stir welded similar and dissimilar sheets of AA2219 and AA7475 aluminium alloys. J. Alloys Compd. 695: 2902-2908

[3] Ahmed M, Ataya S, El-Sayed Seleman M, Ammar H and Ahmed E 2017 Friction stir welding of similar and dissimilar AA7075 and AA5083. J. Mater. Process. Technol. 242: 77-91

[4] Jamshidi Aval H 2015 Microstructure and residual stress distributions in friction stir welding of dissimilar aluminium alloys. Mater. Design 87: 405-413 
[5] Rodriguez R, Jordon J, Allison P, Rushing T and Garcia L 2015 Microstructure and mechanical properties of dissimilar friction stir welding of 6061-to-7050 aluminum alloys. Mater. Design 83: 60-65

[6] Jonckheere C, de Meester B, Denquin A and Simar A 2013 Torque, temperature and hardening precipitation evolution in dissimilar friction stir welds between 6061-T6 and 2014-T6 aluminum alloys. J. Mater. Process. Technol. 213: 826-837

[7] Jamshidi Aval H 2015 Influences of pin profile on the mechanical and microstructural behaviors in dissimilar friction stir welded AA6082-AA7075 butt joint. Mater. Design 67: 413-421

[8] Jamshidi Aval H, Serajzadeh S, Sakharova N A, Kokabi A and Loureiro A 2012 A study on microstructures and residual stress distributions in dissimilar friction-stir welding of AA5086-AA6061. J. Mater. Sci. 47: 5428-5437

[9] Jamshidi Aval H, Serajzadeh S and Kokabi A 2011 Evolution of microstructures and mechanical properties in similar and dissimilar friction stir welding of AA5086 and AA6061. Mater. Sci. Eng. A. 528:8071-8083

[10] Li Y, Murr L and McClure J 1999 Solid-state flow visualiation in the friction stir welding of $2024 \mathrm{Al}$ to $6061 \mathrm{Al}$. Scr. Mater. 40: 1041-1046

[11] Ouyang J and Kovacevic R 2002 Material flow and microstructure in the friction stir butt welds of the same and dissilmilar aluminum alloys. J. Mater. Eng. Perform. 11: 51-63

[12] Amancio-Filho S, Sheikhi S, dos Santos J and Bolfarini C 2008 Preliminary study on the microstructure and mechanical properties of dissimilar friction stir welds in aircraft aluminum alloys 2024-T351 and 6056-T4. J. Mater. Process. Technol. 206: 132-142

[13] Cavaliere P, De Santis A, Panella F and Squillace A 2009 Effect of welding parameters on mechanical and microstructural properties of dissimilar AA6082-AA2024 joints produced by friction stir welding. Mater. Design 30: 609-616
[14] Izadi H, Fallu J, Abdel-Gwad A, Liyanage T and Gerlich A 2013 Analysis of tool geometry in dissimilar Al alloy friction stir welds using optical microscopy and serial sectioning. Sci. Technol. Weld. Join. 18: 307-313

[15] ASTM E92 2017 Standard test methods for Vickers hardness and Knoop hardness of metallic materials. American Society for Testing and Materials, pp. 1-27

[16] ASTM E8-4 A 2004 Standard test methods for tension testing of metallic materials. American Society for Testing and Materials, pp. 1-24

[17] Palanivel R, Koshy Mathews P, Murugan N and Dinaharan I 2012 Effect of tool rotational speed and pin profile on microstructure and tensile strength of dissimilar friction stir welded AA5083-H111 and AA6351-T6 aluminum alloys. Mater. Design 40: 7-16

[18] Zohoor M, Besharati Givi M and Salami P 2012 Effect of processing parameters on fabrication of $\mathrm{Al}-\mathrm{Mg} / \mathrm{Cu}$ composites via friction stir processing. Mater. Design 39: 358-365

[19] Elangovan K, Balasubramanian V and Valliappan M 2007 Influences of tool pin profile and axial force on the formation of friction stir processing zone in AA6061 aluminium alloy. Int. J. Adv. Manuf. Technol. 38: 285-295

[20] Mehta M, De A and DebRoy T 2014 Material adhesion and stresses on friction stir welding tool pins. Sci. Technol. Weld. Join. 19: 534-540

[21] Mishra R and Mahoney M 2007 Friction stir welding and processing. Chapter 4. Materials Park, OH: ASM International, pp. 51-70

[22] Genevois C, Deschamps A and Vacher P 2006 Comparative study on local and global mechanical properties of 2024 T351, 2024 T6 and 5251 O friction stir welds. Mater. Sci. Eng. A 415: 162-170

[23] Jamshidi Aval H and Serajzadeh S 2014 A study on natural aging behavior and mechanical properties of friction stirwelded AA6061-T6 plates. Int. J. Adv. Manuf. Technol. 71: 933-941 